\title{
Kolokasi Bahasa Inggris dalam Tugas Akhir Mahasiswa: Analisis Berbasis Frekuensi dengan Google sebagai Korpus
}

\author{
Tri Nuraniwati', Ashfa F. Lathifah² \\ ${ }^{1}$ Prodi Bahasa Inggris Sekolah Vokasi Universitas Gadjah Mada \\ trinuraniwati@ugm.ac.id \\ ${ }^{2}$ Prodi Bahasa Inggris Sekolah Vokasi Universitas Gadjah \\ ashfafl1@gmail.com
}

\begin{abstract}
This study aims to analyze the search results' frequency of collocations used by students of English Program, Vocational College UGM in their graduating papers (Tugas Akhir) and to show how Google can be used as a practical online corpus for collocations query. Collocations are words that co-occur together in any text and have fixed association. The use of collocations is part of linguistic awareness which determines how language is used in its natural state. Through corpusbased analyses, 1000 collocations are randomly chosen from 10 graduating papers (100 collocations per graduating paper). Using Google search engine, each collocation is entered as key words to find out the frequency of its search hits. The frequency is subsequently categorized into high frequency, medium frequency, and low frequency. From the 1000 collocations, 802 (80.2\%) collocations belong to high-frequency collocations, $120(12 \%)$ collocations are in the category of medium frequency, and 78 (7.8\%) collocations are categorized as low-frequency collocations. The results indicate that students have shown good level of accuracy in using collocations in their academic writing.
\end{abstract}

Key words: graduating paper, collocations, frequency, Google

\section{Intisari}

Penelitian ini bertujuan untuk menganalisis frekuensi hasil pencarian dari kolokasi yang dipakai mahasiswa Prodi Bahasa Inggris Sekolah Vokasi UGM dalam tugas akhir mereka serta menunjukkan bagaimana mesin pencari Google dapat dipakai sebagai korpus daring yang praktis untuk pencarian kolokasi. Kolokasi merupakan kumpulan kata yang cenderung dipakai secara bersama. Penggunaan kolokasi menunjukkan kesadaran metalinguistik di mana sebuah aspek kebahasaan dipakai secara alam oleh penuturnya. Dengan analisis berbasis korpus, 1000 kolokasi yang dipilih secara acak dari 10 tugas akhir (100 kolokasi per tugas akhir). Menggunakan mesin pencari Google, masing-masing kolokasi dimasukkan sebagai kata kunci untuk mengetahui jumlah kemunculannya sebagai hasil pencarian yang kemudian dikategorikan menjadi kolokasi berfrekuensi tinggi, menengah, dan rendah. Hasil yang didapat menunjukkan sebanyak 802 (80,25\%) masuk kategori frekuensi tinggi, 120 (12\%) frekuensi menengah, dan 78 (7.8\%) frekuensi rendah. Hasil ini menunjukkan level akurasi penggunaan kolokasi yang bagus dari mahasiswa dalam tulisan akademik mereka.

Kata kunci: tugas akhir, kolokasi, frekuensi, Google 


\section{Pendahuluan}

Istilah collocation (kolokasi) dikenalkan pertama kali oleh Palmer, seorang pakar pengajaran bahasa Inggris pada tahun 1933, untuk menjelaskan suksesi 2 kata atau lebih yang harus dipelajari sebagai kesatuan yang tak terpisah dan tidak bisa didefinisikan berdasarkan makna masing-masing komponennya (Kennedy, 2002). Istilah kolokasi kemudian dipopulerkan dalam konteks ilmu linguistik oleh Firth pada tahun 1957 untuk menjelaskan kombinasi kata yang mempunyai asosiasi tetap (Gabrielatos, 1994). Contoh yang terkenal untuk menjelaskan asosiasi ini adalah kolokasi 'to take a photo' (memfoto/mengambil foto) di mana kata kerja 'to take' tidak bisa digantikan oleh kata kerja lain semisal 'to make' atau 'to get' karena kata kerja 'to take' dan kata benda 'a photo' sudah memiliki asosiasi tetap.

Dari sudut pandang penutur asli, kemampuan menggunakan kolokasi merupakan aspek alamiah kebahasaan dan merupakan bagian dari kesadaran metalinguitik (metalinguistic awareness), sebuah frasa yang dipakai Koda untuk menjelaskan "the knowledge of rules about language, parts of language, and how language works, or even a simple selfrecognition of one's own language and the forms being used" (Shaw, 2011). Kesadaran metalinguistik muncul karena faktor kebiasaan dan intensitas paparan bahasa. Karena paparan yang terbatas, sebagian besar orang Indonesia yang masuk kategori penutur dan pembelajar bahasa Inggris sebagai bahasa asing (English as a foreign language learners) memerlukan usaha keras untuk mempelajari bentuk dan menghafalkan makna kolokasi sesuai konteks penggunaan baik dalam ragam lisan maupun tulis.

Penggunaan kolokasi dalam ragam lisan sama pentingnya dalam ragam tulis. Dalam ragam lisan, perkataan seseorang akan lebih mudah dipahami apabila penutur menggunakan kolokasi dengan tepat. Dalam ragam tulis, kelancaran penulisan secara gramatikal (tata bahasa) maupun leksikal (kosa kata) salah satunya dipengaruhi oleh apakah penulis menggunakan kolokasi yang tepat atau tidak. Seringkali, penulis yang dalam ini mahasiswa, mengacu pada istilah bahasa Indonesia, kemudian diterjemahkan secara literal ke bahasa Inggris yang 
mengurangi tingkat idiomasi (idiomacy) kebahasaan sebuah tulisan.

May Fan (2009) dalam penelitiannya tentang pemakaian kolokasi oleh pembelajar bahasa Inggris menyimpulkan bahwa penutur asing bahasa Inggris menggunakan kolokasi dengan jumlah lebih sedikit daripada penutur asli dan mengalami kesulitan dalam menggunakan kolokasi secara tepat. Fan juga mendapati adanya pengaruh kombinasi kata pembentuk kolokasi dari bahasa ibu mereka ketika menggunakan Bahasa Inggris. Kondisi seperti ini menurut Fan harus diakomodasi oleh pengajar bahasa Inggris dengan pengajaran kosa kata yang meningkatkan kesadaran pembelajar bahasa akan adanya aspek kebahasaan yang idiomatik dan problematik.

Selain akomodasi pengajar dalam proses, pembelajar bahasa masa kini juga perlu dibekali dengan kemampuan pencarian kolokasi berbasis data (data-driven learning) yang sesuai dengan karakteristik mereka sebagai pribumi digital (digital natives) yang tumbuh dengan fasilitas teknologi dan cakap menggunakan teknologi baik untuk gaya hidup maupun proses pembelajaran.
Digital natives merupakan istilah yang dipakai pertama kali oleh Marc Pensky pada tahun 2001 untuk generasi pembelajar yang sejak kecil sudah terpapar teknologi digital dan menjadikan teknologi sebagai bagian tak terpisahkan dari kehidupan mereka. Dalam menghadapi tipe pembelajar seperti ini, dosen maupun pengajar pada umumnya tidak boleh skeptis dan mau tidak mau harus menjadi imigran digital (digital immigrants) untuk bisa menjadi fasilitator yang baik (Pensky, 2011).

Bagi pribumi digital, kegiatan membuka kamus khusus kolokasi seperti Oxford Collocations Dictionary ataupun bertanya kepada penutur asli sudah tidak lagi populer. Data yang sangat besar ukurannya yang tersedia secara daring merupakan kamus praktis bagi pribumi digital. Dengan bantuan mesin pencari Google, mereka dengan mudah mencari tahu makna dan konteks penggunaan suatu kolokasi.

Agar selaras dengan gaya belajar mahasiswa, pengajar bisa mengajak mereka memanfaatkan mesin pencari Google sebagai salah satu alternatif untuk membantu mencari tahu apakah kolokasi yang mereka pakai sudah tepat atau belum. 
Dengan basis data yang sangat besar, mesin pencari Google dianggap sebagai sebuah korpus daring untuk pembelajaran kosa kata Bahasa Inggris.

Istilah korpus (jamak: korpora) menurut Leech (McEnery, dkk, 2006) mengacu pada koleksi materi tekstual yang disusun dengan tujuan tertentu. Selain yang berwujud piranti lunak, korpora juga tersedia secara daring yang bisa diakses secara gratis dengan ukuran yang sangat besar seperti British National Corpus (BNC), Corpus of Contemporary American English (COCA), dan Michigan Corpus of American Spoken English (MICASE). Korpora tersebut telah cukup lama dikembangkan dan merupakan korpora yang sangat mapan sebagai sumber pembelajaran dan penelitian bahasa, baik lisan maupun tulis.

Walaupun dikategorikan mapan dan lengkap, korpora seperti BNC atau COCA kurang familiar dikalangan mahasiswa. Fakta bahwa sumber teks BNC dan COCA berasal dari penutur asli Bahasa Inggris juga bisa menyiutkan nyali mahasiswa dalam belajar kosa kata. Oleh karena itu dalam penelitian ini dipilih Google yang dianggap sebagai mesin pencari sekaligus korpus daring yang sangat dikenal di kalangan mahasiswa dan dapat diakses sewaktu-waktu.

Dewasa ini mahasiswa sangat tergantung dengan mesin pencari ini sehingga kata 'Google' sekarang identik dengan kata 'mencari.' Kita cukup sering mendengar kalimat "Ya nanti saya Google dulu" atau "Coba di-Google saja" dalam pembelajaran di kelas maupun di luar kelas. Selain tingkat kemutakhiran basis data, kelebihan Google yang lain adalah kemampuannya menampilkan semua aspek kebahasaan dari level kata hingga kalimat yang sangat kompleks, termasuk menampilkan data kolokasi. Dalam hitungan detik, Google mampu menampilkan ratusan juta hasil pencarian. Walaupun tidak semua sumber teks yang masuk ke basis data Google berasal dari sumber yang valid secara gramatika kebahasaan (karena Google juga menampilkan tulisan penutur asing bahasa inggris), jumlah hasil pencarian atau frekuensi kemunculan kolokasi bisa menjadi parameter apakah sebuah kolokasi diterima secara luas dan dianggap tepat. Dalam penelitian berbasis korpus, frekuensi merupakan aspek yang penting, khususnya dalam pembahasan aspek leksikal 
Dengan menggunakan mesin pencari Google penelitian ini menganalisis apakah kolokasi-kolokasi yang dipakai mahasiswa dalam makalah tugas akhir mereka sudah masuk dalam kategori kolokasi yang berfrekuensi tinggi atau belum. Penelitian ini juga menunjukkan cara bagaimana mahasiswa sebagai penutur asing Bahasa Inggris bisa memanfaatkan Google untuk pembelajaran kosa kata Bahasa Inggris khususnya untuk mempelajari kolokasi.

\section{Metode Penelitian}

Data dari penelitian ini adalah 1000 kolokasi yang dipilih secara acak dari 10 makalah tugas akhir mahasiswa Prodi Bahasa Inggris Sekolah Vokasi UGM angkatan 2010 dan 2011. Nama penyusun tugas akhir dan judulnya tidak akan disebutkan dalam penelitian ini. Masing-masing tugas akhir akan dinamai dengan $\mathrm{P} 1, \mathrm{P}_{2}$, dan seterusnya sampai P10.

Tugas akhir merupakan karya tulis mahasiswa Prodi Bahasa Inggris yang wajib ditulis dan diujikan sebagai syarat kelulusan. Tugas akhir bisa berwujud laporan observasi ataupun laporan analitik dari praktik kerja lapangan yang dilakukan mahasiswa pada semester akhir perkuliahan. Tugas akhir umumnya ditulis dalam Bahasa Inggris dengan panjang antara 6000 sampai 10.000 kata yang wajib ditulis mahasiswa sebagai syarat kelulusan. Walaupun sudah melewati proses supervisi dari dosen pembimbing, tulisan mahasiswa tersebut tentu saja tidak sempurna dari aspek gaya, mekanika, dan struktur penulisan. Mahasiswa dengan tingkat kemampuan kebahasaan yang berbeda akan menghasilkan tulisan dengan level gramatikal dan leksikal yang berbeda. Penggunaan aspek idiomatis bahasa khususnya bagaimana mereka menggunakan kolokasi juga akan berbeda level akurasinya.

Dari masing-masing tugas akhir diambil 100 kolokasi secara acak dengan tidak dibatasi bentuk leksikal maupun gramatikalnya. Jumlah kata penyusun per kolokasi juga tidak dibatasi. Ada kolokasi yang tersusun atas 2 kata dan ada yang terbentuk dari 4 kata penyusun.

Penelitian ini menggunakan metode frekuensi berbasis korpus dengan menggunakan mesin pencari Google sebagai korpus daring yang dipadukan dengan metode data-driven learning. Metode frekuensi berbasis korpus merupakan salah 
satu metode yang dipakai dalam ilmu linguistik korpus (corpus linguistics). Cabang dari ilmu linguistik ini mempelajari bagaimana analisis kebahasaan diterapkan untuk kumpulan teks yang menyusun suatu korpus (Meyer, 2002). Metode berbasis frekuensi yang dipakai dalam corpus linguistics terkait erat dengan metalinguistic awareness yang sudah disebutkan dalam bagian sebelumnya. Frekuensi tinggi bisa mencerminkan akurasi suatu aspek kebahasaan oleh penutur asli yang polanya bisa ditiru oleh penutur asing. Kosa kata berfrekuensi tinggi dalam sebuah korpus bisa membantu mahasiswa untuk memahami makna dan penggunaan katakata Bahasa Inggris tertentu secara mendalam untuk keperluan reseptif dan produktif mereka (Romer, 2008).

Terkait data-driven learning, metode pembelajaran yang digagas oleh Johns di tahun 1994 ini dipakai untuk memberikan gambaran kepada mahasiswa bagaimana fenomena kebahasaan dapat dilihat dalam konteks yang lebih nyata melalui korpora yang sumber teksnya berasal dari penutur Bahasa Inggris, bukan dari kamus ataupun buku yang ditulis para ahli yang bersifat didaktif (Meyer, 2002). Hal ini sesuai dengan pernyataan Anderson dan Corbett (2009) "The careful analysis of corpora can give insights into (i) how language is really used, rather than how people think it is used and (ii) how it is commonly and typically used."

Pembelajaran berbasis korpus berbeda dengan pembelajaran melalui buku teks maupun kamus yang cenderung menunjukkan bagaimana seharusnya aspek kebahasaan dipakai, bukan bagaimana pada umunya aspek tersebut dipakai oleh penggunanya.

Data berupa 1000 kolokasi dipilih dari 10 tugas akhir yang dipilih secara acak dan kemudian dimasukkan satu per satu ke mesin pencari Google untuk dicari jumlah hasil pencariannya. Pencarian tidak menggunakan metode khusus seperti penggunaan metode Boolean operator (penggunaan AND, OR, NOT or AND NOT) maupun penggunaan tanda kutipan langsung (“...”) untuk membatasi hasil pencarian. Kolokasi diketik secara langsung di laman pencarian Google dan dicatat jumlah frekuensi kemunculannya (search hits). Walaupun tidak sulit, proses ini memerlukan waktu yang cukup lama karena terdapat 1000 kolokasi yang harus dicari frekuensinya. Kecepatan mendapatkan data 
frekuensi juga sangat tergantung dengan kecepatan akses internet.

Seperti kita ketahui, Google melakukan pencarian sebanyak mungkin terhadap jutaan situs yang terdapat dalam world wide web yang jumlahnya akan berkurang dan bertambah sewaktu-waktu, maka frekuensi hasil pencarian untuk kolokasi tertentu juga akan berbeda setiap saat.
Data jumlah hasil pencarian dalam penelitian ini diambil pada bulan Februari 2017 dan contohnya dapat dilihat di Gambar 1 berikut ini. Gambar 1 merupakan hasil tangkapan layar dari hasil pencarian untuk kolokasi tourist destinations yang berasal dari tugas akhir 1 (P1):

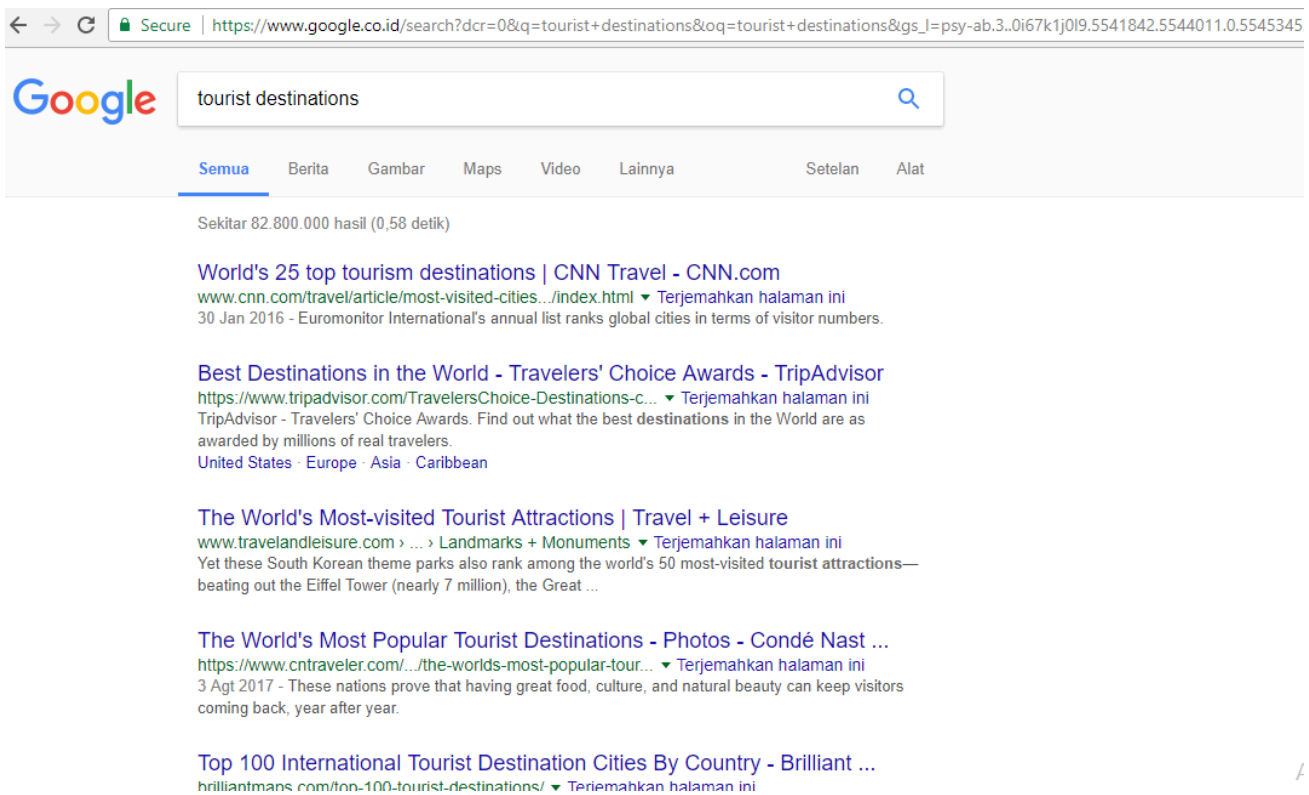

Gambar 1. Hasil Tangkapan layar untuk kolokasi 'tourist destinations'

Dalam waktu 0,58 detik, Google mampu menampilkan 82.800 .000 hasil pencarian untuk kolokasi tersebut.
Contoh lain bisa dilihat di gambar 2 untuk pencarian kolokasi Islamic boarding school berikut ini: 


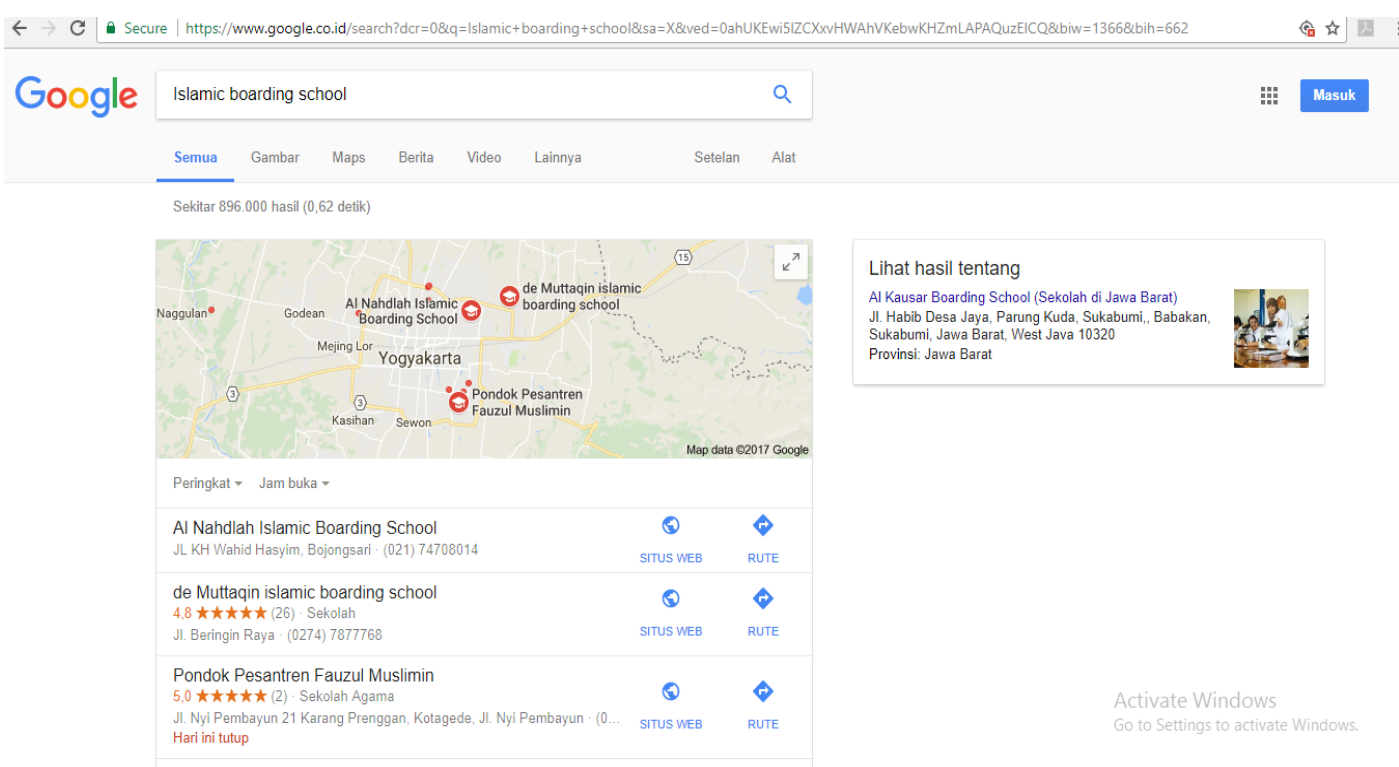

Gambar 2. Hasil tangkapan layar untuk kolokasi 'Islamic boarding school'

Dalam waktu 0,62 detik, Google mampu menampilkan 896.000 hasil pencarian.

Hasil pencarian yang berupa frekuensi kemunculan dari 1000 kolokasi yang memiliki jumlah hasil pencarian kurang dari 1 digunakan sebagai data penelitian ini juta. Kategorisasi ini dibuat berdasarkan pola selanjutnya diklasifikasikan menjadi tiga pencarian umum yang ada di mesin pencari kategori: frekuensi tinggi (high frequency), Google.

frekuensi menengah (medium frequency),

Tabel 1 berikut ini memuat contoh dan frekuensi rendah (low frequency). jumlah frekuensi hasil pencarian untuk 10 Kategori frekuensi tinggi mengacu pada kolokasi yang diambil dari tugas akhir 1(P1):

Table 1. Contoh hasil pencarian kolokasi tugas akhir 1 (P1)

\begin{tabular}{|r|l|r|}
\hline No. & \multicolumn{1}{|c|}{ P1 } & \multicolumn{1}{|c|}{$\begin{array}{c}\text { Jumlah Hasil } \\
\text { Pencarian Google }\end{array}$} \\
\hline 1 & tourist destinations & 82.800 .000 \\
\hline 2 & religious tourism & 1.770 .000 \\
\hline 3 & culinary tourism & 2.350 .000 \\
\hline 4 & handicraft tourism & 500.000 \\
\hline
\end{tabular}




\begin{tabular}{|r|l|r|}
\hline 5 & educational tourism & 1.960 .000 \\
\hline 6 & overall area & 839.000 .000 \\
\hline 7 & land area & 62.600 .000 \\
\hline 8 & service point & 51.300 .000 \\
\hline 9 & natural attraction & 116.000 .000 \\
\hline 10 & tourist view & 119.000 .000 \\
\hline
\end{tabular}

Sumber: Data Primer

Dari tabel 1 terlihat kolokasi tourist kategori frekuensi menengah. Sedangkan destinations, overall area, natural attraction, handicraft tourism masuk ke kategori land area, service point, dan tourist view kolokasi dengan frekuensi rendah. masuk kategori kolokasi berfrekuensi tinggi. Contoh lain dari frekuensi hasil pencarian Religious tourism, culinary tourism, dan untuk 10 kolokasi dalam tugas akhir 5 (P5) educational tourism termasuk kolokasi dapat dilihat di tabel 2 berikut ini:

Tabel 2. Contoh hasil pencarian kolokasi tugas akhir 5 (P5)

\begin{tabular}{|c|c|c|}
\hline No. & P5 & $\begin{array}{c}\text { Jumlah Hasil } \\
\text { Pencarian } \\
\text { Google }\end{array}$ \\
\hline 1 & brief profile & 174.000 .000 \\
\hline 2 & modern Islamic boarding school & 480.000 \\
\hline 3 & story of establishment & 282.000 .000 \\
\hline 4 & Islamic boarding school & 896.000 \\
\hline 5 & boarding school & 18.400 .000 \\
\hline 6 & greatly indebted & 3.150 .000 \\
\hline 7 & royal title & 322.000 .000 \\
\hline 8 & fourth generation & 6.990 .000 \\
\hline 9 & three kilometers away & 25.900 .000 \\
\hline 10 & forested area & 8.420 .000 \\
\hline
\end{tabular}

Sumber: Data Primer

Dari tabel 2 bisa dilihat kolokasi brief profile, kategori frekuensi tinggi. Greatly indebted, story of establishment, boarding school, royal fourth generation, dan forested area masuk title, dan three kilometers away masuk kategori frekuensi menengah, sedangkan 
modern Islamic boarding school dan Islamic boarding school berada pada kategori kolokasi berfrekuensi rendah. Contoh hasil pencarian yang lebih lengkap untuk tugas akhir $1(\mathrm{P} 1)$ sampai tugas akhir $10(\mathrm{P} 10)$ dapat dilihat di lampiran akhir penelitian ini.

\section{Hasil Dan Pembahasan}

Setelah penelusuran jumlah hasil pencarian masing-masing kolokasi didapatkan dan dikategorikan level frekuensinya, peneliti selanjutnya menghitung berapa jumlah kolokasi berfrekuensi tinggi, menengah, dan rendah dari masing-masing tugas akhir yang menjadi sampel. Hasil pencarian frekuensi kolokasi yang digunakan mahasiswa dalam tugas akhir mereka dapat diringkas dalam tabel 3 berikut ini:

Tabel 3. Jumlah hasil pencarian kolokasi

\begin{tabular}{|l|c|c|c|c|c|c|c|c|c|c|c|c|}
\hline \multicolumn{1}{|c|}{ FREKUENSI } & P1 & P2 & P3 & P4 & P5 & P6 & P7 & P8 & P9 & P10 & TOTAL & \% \\
\hline Frekuensi tinggi & 80 & 76 & 83 & 75 & 74 & 81 & 86 & 87 & 81 & 79 & 802 & 80,2 \\
\hline $\begin{array}{l}\text { Frekuensi } \\
\text { menengah }\end{array}$ & 13 & 10 & 7 & 18 & 16 & 13 & 8 & 11 & 11 & 13 & 120 & 12 \\
\hline \begin{tabular}{l} 
Frekuensi rendah \\
\hline
\end{tabular} & 7 & 14 & 10 & 7 & 10 & 6 & 6 & 2 & 8 & 8 & 78 & 7,8 \\
\hline
\end{tabular}

Sumber: Data Primer

Dari 1000 kolokasi yang dianalisis, 80,2 penggunaan frekuensi tinggi dengan \% (802 kolokasi) masuk kategori kolokasi persentase lebih dari $70 \%$. Frekuensi tinggi dengan frekuensi tinggi; 12 \% (120 kolokasi) dengan jumlah paling rendah ditunjukkan dikategorikan sebagai kolokasi berfrekuensi oleh tugas akhir 2 (P5) sejumlah 74 kolokasi. menengah; dan $7,8 \%$ (78 kolokasi) masuk Yang perlu diperhatikan adalah daftar kategori kolokasi berfrekuensi rendah. kolokasi dengan frekuensi rendah yang dapat Masing-masing tugas akhir menunjukkan dilihat di tabel 4 berikut: 
Tabel 4. Daftar kolokasi dengan kategori low frequency

\begin{tabular}{|c|c|c|c|c|c|c|c|c|c|}
\hline \multicolumn{10}{|c|}{ Low-frequency collocations } \\
\hline P1 & $\mathrm{P} 2$ & $\mathrm{P}_{3}$ & $\mathrm{P} 4$ & $\mathrm{P}_{5}$ & P6 & $\mathrm{P7}$ & P8 & P9 & P10 \\
\hline $\begin{array}{l}\text { handicraft } \\
\text { tourism }\end{array}$ & $\begin{array}{l}\text { several } \\
\text { healers }\end{array}$ & $\begin{array}{l}\text { spirited } \\
\text { leadership }\end{array}$ & $\begin{array}{l}\text { talented } \\
\text { business } \\
\text { men }\end{array}$ & $\begin{array}{l}\text { modern } \\
\text { Islamic } \\
\text { boarding } \\
\text { school }\end{array}$ & $\begin{array}{l}\text { reign of } \\
\text { Han } \\
\text { dynasty }\end{array}$ & sit calmly & $\begin{array}{l}\text { city of } \\
\text { gudeg }\end{array}$ & $\begin{array}{l}\text { customer } \\
\text { buying } \\
\text { habits }\end{array}$ & $\begin{array}{l}\text { ritual sura } \\
\text { tradition }\end{array}$ \\
\hline $\begin{array}{l}\text { favorite } \\
\text { tourist } \\
\text { destinatio } \\
\mathrm{n}\end{array}$ & $\begin{array}{l}\text { miraculou } \\
\text { sly } \\
\text { recovere } \\
\text { d }\end{array}$ & $\begin{array}{l}\text { administrati } \\
\text { vely } \\
\text { managed }\end{array}$ & $\begin{array}{l}\text { distributo } \\
\text { r of } \\
\text { consumer } \\
\text { electronic } \\
\mathrm{s}\end{array}$ & $\begin{array}{l}\text { Islamic } \\
\text { boarding } \\
\text { school }\end{array}$ & $\begin{array}{l}\text { gift } \\
\text { shop } \\
\text { noodles }\end{array}$ & $\begin{array}{l}\text { broadcasted } \\
\text { publicity }\end{array}$ & $\begin{array}{l}\text { indeed } \\
\text { purposef } \\
\text { ully }\end{array}$ & $\begin{array}{l}\text { serat alam } \\
\text { home } \\
\text { industry }\end{array}$ & $\begin{array}{l}\text { heirloom } \\
\text { carrier }\end{array}$ \\
\hline $\begin{array}{l}\text { souvenir } \\
\text { markets }\end{array}$ & $\begin{array}{l}\text { swallows } \\
\text { nests } \\
\text { hunters }\end{array}$ & $\begin{array}{l}\text { interdisciplin } \\
\text { ary and } \\
\text { condensed } \\
\text { research }\end{array}$ & $\begin{array}{l}\text { vendor } \\
\text { neutral }\end{array}$ & $\begin{array}{l}\text { survival of } \\
\text { Gontor }\end{array}$ & $\begin{array}{l}\text { medium } \\
\text {-class } \\
\text { restaura } \\
\text { nt }\end{array}$ & $\begin{array}{l}\text { English news } \\
\text { program }\end{array}$ & & $\begin{array}{l}\text { handicraft } \\
\text { products }\end{array}$ & $\begin{array}{l}\text { ritual } \\
\text { processio } \\
\mathrm{n}\end{array}$ \\
\hline $\begin{array}{l}\text { perusal of } \\
\text { the } \\
\text { history }\end{array}$ & $\begin{array}{l}\text { biggest } \\
\text { producer }\end{array}$ & $\begin{array}{l}\text { condensed } \\
\text { research }\end{array}$ & $\begin{array}{l}\text { optimally } \\
\text { comforta } \\
\text { ble indoor } \\
\text { environm } \\
\text { ent }\end{array}$ & $\begin{array}{l}\text { plaited } \\
\text { mats }\end{array}$ & $\begin{array}{l}\text { other } \\
\text { stalls }\end{array}$ & $\begin{array}{l}\text { commemora } \\
\text { tion speech }\end{array}$ & & $\begin{array}{l}\text { natural } \\
\text { fiber } \\
\text { crafter }\end{array}$ & $\begin{array}{l}\text { different } \\
\text { golden } \\
\text { eras }\end{array}$ \\
\hline $\begin{array}{l}\text { tourism } \\
\text { object } \\
\text { gate }\end{array}$ & $\begin{array}{l}\text { swallows } \\
\text { nests } \\
\text { cultivatio } \\
\mathrm{n}\end{array}$ & $\begin{array}{l}\text { institutional } \\
\text { cooperation }\end{array}$ & $\begin{array}{l}\text { water } \\
\text { chillers }\end{array}$ & $\begin{array}{l}\text { Indonesia } \\
\mathrm{n} \\
\text { personalit } \\
\mathrm{y}\end{array}$ & $\begin{array}{l}\text { noodle } \\
\text { stall }\end{array}$ & $\begin{array}{l}\text { VHF } \\
\text { transmitter }\end{array}$ & & $\begin{array}{l}\text { unavailabi } \\
\text { lity of } \\
\text { showroo } \\
\text { m }\end{array}$ & $\begin{array}{l}\text { supernatu } \\
\text { ral and } \\
\text { magical } \\
\text { phenome } \\
\text { na }\end{array}$ \\
\hline $\begin{array}{l}\text { optimum } \\
\text { managem } \\
\text { ent }\end{array}$ & $\begin{array}{l}\text { rattled } \\
\text { sound }\end{array}$ & $\begin{array}{l}\text { audio-lingual } \\
\text { classes }\end{array}$ & $\begin{array}{l}\text { variable } \\
\text { refrigeran } \\
\text { t volume }\end{array}$ & $\begin{array}{l}\text { Islamic } \\
\text { brotherho } \\
\text { od }\end{array}$ & $\begin{array}{l}\text { wet } \\
\text { noodle }\end{array}$ & & & $\begin{array}{l}\text { batik } \\
\text { materials }\end{array}$ & $\begin{array}{l}\text { lineage of } \\
\text { kingdom }\end{array}$ \\
\hline \multirow[t]{8}{*}{$\begin{array}{l}\text { visitor } \\
\text { annularity }\end{array}$} & $\begin{array}{l}\text { strong } \\
\text { Javanese } \\
\text { culture }\end{array}$ & $\begin{array}{l}\text { phonetics } \\
\text { lab }\end{array}$ & $\begin{array}{l}\text { variable } \\
\text { refrigeran } \\
\text { t flow }\end{array}$ & & & & & $\begin{array}{l}\text { househol } \\
\mathrm{d} \\
\text { ornament } \\
\mathrm{s}\end{array}$ & $\begin{array}{l}\text { genie } \\
\text { palace }\end{array}$ \\
\hline & $\begin{array}{l}\text { Javanese } \\
\text { poem }\end{array}$ & $\begin{array}{l}\text { Javanese } \\
\text { instrumental }\end{array}$ & $\begin{array}{l}\text { routine } \\
\text { activities } \\
\text { and } \\
\text { programs }\end{array}$ & & & & & $\begin{array}{l}\text { batik } \\
\text { necklace }\end{array}$ & \\
\hline & $\begin{array}{l}\text { swallow } \\
\text { nest }\end{array}$ & $\begin{array}{l}\text { graduate } \\
\text { designations }\end{array}$ & $\begin{array}{l}\text { Waqf } \\
\text { maintena } \\
\text { nce and } \\
\text { enlargem } \\
\text { ent }\end{array}$ & & & & & & \\
\hline & $\begin{array}{l}\text { swallow } \\
\text { bird habit }\end{array}$ & $\begin{array}{l}\text { unstructure } \\
\text { d curriculum }\end{array}$ & waqf land & & & & & & \\
\hline & stiff wing & & $\begin{array}{l}\text { well } \\
\text { qualified } \\
\text { Muslim } \\
\text { leader } \\
\end{array}$ & & & & & & \\
\hline & $\begin{array}{l}\text { chalk } \\
\text { cave }\end{array}$ & & & & & & & & \\
\hline & $\begin{array}{l}\text { spacious } \\
\text { tail }\end{array}$ & & & & & & & & \\
\hline & $\begin{array}{l}\text { loud and } \\
\text { rattled } \\
\text { sound }\end{array}$ & & & & & & & & \\
\hline
\end{tabular}

Sumber: Data Primer 


\section{Kesimpulan}

Kolokasi dengan kategori low

frequency mengindikasikan beberapa hal:

1. Adanya faktor penerjemahan literal yang mempengaruhi bagaimana mahasiswa menyusun kolokasi secara literal kata per kata dalam kalimatkalimat mereka. Sebagai contoh kolokasi chalk cave yang dipakai di tugas akhir 2 (P2). Mahasiswa terpengaruh dengan istilah 'goa kapur' dalam bahasa Indonesia. Kata 'kapur' harusnya diterjemahkan menjadi 'limestone' karena kata 'chalk’ mengacu pada 'kapur' yang dipakai untuk menulis.

2. Adanya istilah lokal yang sudah terserap Bahasa Inggris namun belum banyak dipakai karena merupakan culturally-bound words seperti kolokasi Islamic boarding school yang dalam bahasa Indonesia sering disebut sebagai pesantren dan batik necklace (kalung batik) yang keberadaannya dalam basis data Google tidak banyak.
Dengan presentase kolokasi berfrekuensi tinggi sebanyak 80,2\%, hasil penelitian ini menunjukkan bahwa mahasiswa penulis tugas akhir di Prodi Bahasa Inggris Sekolah Vokasi telah menunjukkan kemampuan penggunaan kolokasi yang bagus dalam tulisan akademik mereka, yang berarti kemampuan reseptif dan produktif mereka dalam menggunakan kosa kata akademik bahasa Inggris sudah cukup mumpuni.

Bagi mahasiswa yang masih menjalani studi, fasilitasi penggunaan korpus daring harus terus dikembangkan oleh para dosen untuk memperbaiki penguasaan kosa kata mereka. Penggunaan Google sebagai korpus daring dalam penelitian ini terbukti efektif dan dapat diadopsi oleh mahasiswa untuk membantu memastikan level akurasi dan keberterimaan penggunaan kolokasi tertentu. Menurut Fletcher (2002), sumber daring termasuk di dalamnya korpora memiliki keuntungan dalam hal kemutakhiran, multimodalitas, dan ketersediaan data dengan jumlah sangat besar namun dengan biaya minimal. Untuk mesin pencari Google, konten web yang 
selalu bertambah setiap saat menambah kemutakhiran basis data Google sebagai mesin pencari. Bentuk data yang beragam

\section{Daftar Pustaka}

Anderson W. \& J. Corbett. (2009). Exploring English with Online Corpora: An Introduction. London: Palgrave.

Fan, May. (2009). An Exploratory study of collocational use by ESL students-A task based approach. System, 37, 110-123.

Fletcher, William. (2002). Making the Web More Useful as a Source for Linguistic Corpora. Corpus Linguistics in North America 2002: Selections from the Fourth North American Symposium of the American Association for Applied Corpus Linguistics.

http://kwicfinder.com/AAACL2002whf.p df Accessed 16.04.13

Gabrielatos, Constatinos.

(1994). Collocations: Pedagogical implications and their treatment in pedagogical materials. Unpublished essay. Research Centre for English and Applied Linguistics. University of Cambridge.

Kennedy, Graeme. (2003). Amplifier Collocations in the British National Corpus: Implications for English juga mengakomodasi proses pembelajaran kosa kata yang bervariasi.

Language Teaching. TESOL Quarterly 37 (3), 467-477.

McEnery, Tony et.al. (2006). Corpus-Based Language Studies: An Advanced Resource Book. London: Routledge.

Meyer, Charles F. (2002). English Corpus Linguistics: An Introduction. Cambridge: CUP.

Prensky, Marc. (2012) From Digital Natives to Digital Wisdom: Hopeful Essays for $21^{\text {st }}$ Century Education. http://marcprensky.com/writing/PrenskyIntro_to_From_DN_to_DW.pdf

Romer, U. (2008) Corpora and language teaching. In A. Ludeling \& M. Kyoto (Eds.), Corpus linguistics: An international handbook (Vol. 1, pp. 112-130). Berlin: Mouton de Gruyter.

Shaw, Erin. (2011). Teaching Vocabulary Through Data-driven Learning. Idaho: BYU. 


\section{Lampiran 1}

\section{Daftar frekuensi hasil pencarian $\mathrm{P}_{1}-\mathrm{P}_{3}$}

\begin{tabular}{|c|c|c|c|c|c|c|}
\hline No. & P1 & $\begin{array}{c}\text { Jumlah Hasil } \\
\text { Pencarian } \\
\text { Google }\end{array}$ & P2 & $\begin{array}{c}\text { Jumlah Hasil } \\
\text { Pencarian } \\
\text { Google }\end{array}$ & $P_{3}$ & $\begin{array}{c}\text { Jumlah Hasil } \\
\text { Pencarian } \\
\text { Google }\end{array}$ \\
\hline 1 & large number & 322.000 .000 & natural resources & 438.000 .000 & six times & 31.900 .000 \\
\hline 2 & tourist destination & 8.790 .000 & tourism places & 338.000 .000 & earliest state university & 13.600 .000 \\
\hline 3 & tourist destinations & 90.000 .000 & good potentials & 24.800 .000 & new faculties & 21.000 .000 \\
\hline 4 & $\begin{array}{c}\text { main tourist } \\
\text { destination }\end{array}$ & 52.200 .000 & good potentials place & 825.000 .000 & $\begin{array}{c}\text { most recent } \\
\text { development }\end{array}$ & 1.050 .000 .000 \\
\hline 5 & capital city & 64.600 .000 & $\begin{array}{c}\text { different kinds of } \\
\text { business }\end{array}$ & 242.000 .000 & diploma program & 167.000 .000 \\
\hline 6 & historical place & 629.000 .000 & special gifts & 230.000 .000 & eight study programs & 214.000 .000 \\
\hline 7 & natural atmosphere & 247.000 .000 & $\begin{array}{c}\text { culinary tourism } \\
\text { packages }\end{array}$ & 12.200 .000 & Indonesian culture & 29.400 .000 \\
\hline 8 & various thing & 480.000 .000 & home furniture & 360.000 .000 & $\begin{array}{l}\text { language learning } \\
\text { program }\end{array}$ & 540.000 .000 \\
\hline 9 & tourism potential & 108.000 .000 & $\begin{array}{c}\text { economic and cultural } \\
\text { significance }\end{array}$ & 110.000 .000 & foreign students & 16.200 .000 \\
\hline 10 & historical tourism & 106.000 .000 & several healers & 642.000 & another faculty & 255.000 .000 \\
\hline 11 & nature tourism & 161.000 .000 & big prize & 84.400 .000 & educational institution & 234.000 .000 \\
\hline 12 & cultural tourism & 179.000 .000 & next day & 369.000 .000 & cultural research center & 12.000 .000 \\
\hline 13 & religious tourism & 1.770 .000 & miraculously recovered & 514.000 & International level & 1.390 .000 .000 \\
\hline 14 & culinary tourism & 2.350 .000 & very healthy & 484.000 .000 & interests of humanity & 44.400 .000 \\
\hline 15 & handicraft tourism & 500.000 & very unique & 848.000 .000 & higher education & 915.000 .000 \\
\hline 16 & educational tourism & 1.960 .000 & very well-protected & 16.400 .000 & high quality & 904.000 .000 \\
\hline 17 & overall area & 839.000 .000 & swallows nests hunters & 523.000 & spirited leadership & 580.000 \\
\hline 18 & land area & 62.600 .000 & biggest producer & 404.000 & cultural sciences & 3.090 .000 \\
\hline 19 & things we know & 313.000 .000 & some rituals & 44.200 .000 & progress of education & 677.000 .000 \\
\hline
\end{tabular}




\begin{tabular}{|c|c|c|c|c|c|c|}
\hline 20 & natural attraction & 116.000 .000 & some food & 1.470 .000 .000 & $\begin{array}{c}\text { national interests and } \\
\text { humanity }\end{array}$ & 2.390 .000 \\
\hline 21 & beautiful caves & 42.800 .000 & $\begin{array}{c}\text { potentials and cultural } \\
\text { values }\end{array}$ & 180.000 .000 & culture community & 953.000 .000 \\
\hline 22 & $\begin{array}{c}\text { located } \\
\text { approximately }\end{array}$ & 11.300 .000 & research questions & 1.150 .000 .000 & various parties & 499.000 .000 \\
\hline 23 & southern village & 3.220 .000 & cultural values & 253.000 .000 & $\begin{array}{c}\text { organization and faculty } \\
\text { management }\end{array}$ & 136.000 .000 \\
\hline 24 & tourist views & 119.000 .000 & $\begin{array}{c}\text { swallows nests } \\
\text { cultivation }\end{array}$ & 471.000 & educational purposes & 409.000 .000 \\
\hline 25 & sacred places & 8.890 .000 & citizens point of view & 17.200 .000 & high integrity & 20.200 .000 \\
\hline 26 & tourism department & 201.000 .000 & $\begin{array}{c}\text { qualitative and } \\
\text { quantitative analysis }\end{array}$ & 2.560 .000 & $\begin{array}{c}\text { changes and progress of } \\
\text { knowledge }\end{array}$ & 307.000 .000 \\
\hline 27 & $\begin{array}{c}\text { government } \\
\text { business charge }\end{array}$ & 516.000 .000 & certain methods & 790.000 .000 & community problems & 769.000 .000 \\
\hline 28 & $\begin{array}{c}\text { government } \\
\text { business }\end{array}$ & 1.460 .000 .000 & direct observation & 10.300 .000 & $\begin{array}{l}\text { knowledge and } \\
\text { technology skills }\end{array}$ & 293.000 .000 \\
\hline 29 & culture promotion & 320.000 .000 & rattled sound & 498.000 & productive activities & 110.000 .000 \\
\hline 30 & increasing visitors & 103.000 .000 & additional information & 592.000 .000 & community services & 150.000 .000 \\
\hline 31 & $\begin{array}{c}\text { development } \\
\text { strategies }\end{array}$ & 347.000 .000 & $\begin{array}{c}\text { more detailed } \\
\text { information }\end{array}$ & 211.000 .000 & basic sciences & 31.200 .000 \\
\hline 32 & $\begin{array}{c}\text { favorite tourist } \\
\text { destination }\end{array}$ & 30.400 & four chapters & 120.000 .000 & $\begin{array}{c}\text { quality of learning } \\
\text { process }\end{array}$ & 475.000 .000 \\
\hline 33 & $\begin{array}{c}\text { favorite tourism } \\
\text { destination }\end{array}$ & 25.300 .000 & study objectives & 232.000 .000 & learning activities & 772.000 .000 \\
\hline 34 & tourism subject & 224.000 .000 & next chapter & 39.200 .000 & $\begin{array}{c}\text { administratively } \\
\text { managed }\end{array}$ & 437.000 \\
\hline 35 & completing facility & 106.000 .000 & each species & 297.000 .000 & name management & 1.290 .000 .000 \\
\hline 36 & more attractive & 53.000 .000 & usually added & 629.000 .000 & $\begin{array}{l}\text { university compulsory } \\
\text { courses }\end{array}$ & 27.400 .000 \\
\hline 37 & research methods & 18.000 .000 & sign of a place & 1.550 .000 .000 & $\begin{array}{c}\text { faculty compulsory } \\
\text { courses } \\
\end{array}$ & 15.900 .000 \\
\hline 38 & library research & 1.210 .000 .000 & strong Javanese cul ture & 145.000 & each program of study & 1.010 .000 .000 \\
\hline 39 & accurate database & 188.000 .000 & other region & 1.560 .000 .000 & $\begin{array}{c}\text { student lectures } \\
\text { schedule }\end{array}$ & 99.600 .000 \\
\hline
\end{tabular}




\begin{tabular}{|c|c|c|c|c|c|c|}
\hline 40 & specific information & 1.160 .000 .000 & cultural things & 387.000 .000 & $\begin{array}{c}\text { courses of study } \\
\text { programs }\end{array}$ & 310.000 .000 \\
\hline 41 & real fact & 877.000 .000 & traditional dances & 24.200 .000 & research funding & 276.000 .000 \\
\hline 42 & second chapter & 30.100 .000 & Javanese poem & 281.000 & $\begin{array}{c}\text { various types and } \\
\text { qualifications } \\
\end{array}$ & 87.100 .000 \\
\hline 43 & third chapter & 446.000 .000 & administrative logo & 404.000 .000 & $\begin{array}{c}\text { research program } \\
\text { implementation }\end{array}$ & 7.940 .000 \\
\hline 44 & last chapter & 667.000 .000 & region logo & 1.040 .000 .000 & competition system & 403.000 .000 \\
\hline 45 & research objectives & 236.000 .000 & capital income & 13.000 .000 & great topic & 427.000 .000 \\
\hline 46 & local government & 374.000 .000 & strong bond & 211.000 .000 & $\begin{array}{l}\text { interdisciplinary and } \\
\text { condescend research }\end{array}$ & 101.000 \\
\hline 47 & lodging facilities & 141.000 .000 & each other & 975.000 .000 & condescend research & 938.000 \\
\hline 48 & souvenir markets & 557.000 & aerial bird & 27.500 .000 & $\begin{array}{c}\text { implementation of this } \\
\text { system }\end{array}$ & 326.000 .000 \\
\hline 49 & certain days & 948.000 .000 & dark black color & 317.000 .000 & other research & 1.960 .000 .000 \\
\hline 50 & $\begin{array}{l}\text { established } \\
\text { procedures }\end{array}$ & 358.000 .000 & fly fast & 136.000 .000 & institutional cooperation & 886.000 \\
\hline 51 & $\begin{array}{l}\text { perusal of the } \\
\text { history }\end{array}$ & 537.000 & medium body size & 287.000 .000 & staff researcher & 99.300 .000 \\
\hline 52 & major tourist visits & 97.700 .000 & ceiling of house & 130.000 .000 & study centers & 25.000 .000 \\
\hline 53 & tourist visits & 67.100 .000 & good minerals & 23.600 .000 & other studies & 781.000 .000 \\
\hline 54 & $\begin{array}{l}\text { horse-drawn } \\
\text { carriage }\end{array}$ & 1.140 .000 & six kinds & 152.000 .000 & individual cooperation & 231.000 .000 \\
\hline 55 & art potency & 16.400 .000 & swallow nest & 671.000 & prepatory institution & 24.400 .000 \\
\hline 56 & $\begin{array}{c}\text { promotional } \\
\text { program }\end{array}$ & 5.000 .000 & swallow bird habit & 740.000 & largely documented & 83.600 .000 \\
\hline 57 & natural potency & 18.100 .000 & many people & 2.300 .000 .000 & research activities & 2.640 .000 .000 \\
\hline 58 & great waves & 5.030 .000 & body size & 924.000 .000 & last three years & 354.000 .000 \\
\hline 59 & favorite thing & 26.700 .000 & feathers color & 17.300 .000 & $\begin{array}{c}\text { community service } \\
\text { activities }\end{array}$ & 61.000 .000 \\
\hline 60 & cultural value & $451.000,000$ & steep cliff & 11.900 .000 & more study programs & 754.000 .000 \\
\hline 61 & increasing number & 376.000 .000 & small insects & 75.500 .000 & $\begin{array}{c}\text { community service } \\
\text { programs }\end{array}$ & 105.000 .000 \\
\hline
\end{tabular}




\begin{tabular}{|c|c|c|c|c|c|c|}
\hline 62 & tourism object gate & 429.000 & moist place & 53.700 .000 & qualified proposals & 61.100 .000 \\
\hline 63 & service point & 51.300 .000 & second similarity & 45.300 .000 & $\begin{array}{c}\text { community service } \\
\text { funding }\end{array}$ & 35.800 .000 \\
\hline 64 & great influence & 445.000 .000 & all swallow & 59.300 .000 & cost of implementation & 324.000 .000 \\
\hline 65 & safety point & 962.000 .000 & more number & 3.850 .000 .000 & field of study & 1.160 .000 .000 \\
\hline 66 & appropriate tourism & 88.600 .000 & same tasks & 233.000 .000 & $\begin{array}{c}\text { relevant program of } \\
\text { study }\end{array}$ & 502.000 .000 \\
\hline 67 & visitor origin & 47.200 .000 & similar body shape & 4.920 .000 & synergy of cooperation & 7.450 .000 \\
\hline 68 & tourist interests & 32.800 .000 & good colony & 19.300 .000 & $\begin{array}{c}\text { community service } \\
\text { program interdisciplinary }\end{array}$ & 2.220 .000 \\
\hline 69 & $\begin{array}{c}\text { optimum } \\
\text { management }\end{array}$ & 922.000 & strong claw & 4.520 .000 & some facilities & 600.000 .000 \\
\hline 70 & closely related & 82.300 .000 & house ceiling & 159.000 .000 & books collection & 639.000 .000 \\
\hline 71 & $\begin{array}{c}\text { promotional } \\
\text { strategy }\end{array}$ & 1.160 .000 & good environment & 944.000 .000 & several computers & 141.000 .000 \\
\hline 72 & $\begin{array}{c}\text { main tourism } \\
\text { destination }\end{array}$ & 71.600 .000 & next generation & 233.000 .000 & language lab & 17.200 .000 \\
\hline 73 & tourism area & 573.000 .000 & white color nest & 3.550 .000 & audio-lingual classes & 101.000 \\
\hline 74 & continuing efforts & 17.600 .000 & white nest & 27.200 .000 & student capacity & 323.000 .000 \\
\hline 75 & tourism products & 9.850 .000 & white swallow bird & 8.110 .000 & computer lab & 15.900 .000 \\
\hline 76 & promotion staff & 480.000 .000 & brown and black feather & 3.700 .000 & computer system & 1.260 .000 .000 \\
\hline 77 & operational phases & 48.700 .000 & grey and brown feather & 5.410 .000 & phonetics lab & 391.000 \\
\hline 78 & promotion activities & 480.000 .000 & high voice & 433.000 .000 & Javanese instrumental & 251.000 \\
\hline 79 & $\begin{array}{c}\text { various promotion } \\
\text { activities }\end{array}$ & 167.000 .000 & dark brown eyes & 13.400 .000 & photocopy service & 21.900 .000 \\
\hline 80 & relevant colleges & 116.000 .000 & black beak and foot & 4.140 .000 & education process & 1.230 .000 .000 \\
\hline 81 & various exhibition & 122.000 .000 & stiff wing & 672.000 & four semester & 135.000 .000 \\
\hline 82 & national level & 1.580 .000 .000 & fly strongly & 59.900 .000 & minimum credit & 640.000 .000 \\
\hline 83 & promotion activity & 268.000 .000 & low place & 59.700 .000 & maximum time limit & 38.600 .000 \\
\hline 84 & first businesses & 690.000 .000 & tall tree & 20.900 .000 & study period & 17.400 .000 \\
\hline 85 & before doing & 1.150 .000 .000 & reef space & 35.800 .000 & second semester & 6.430 .000 \\
\hline
\end{tabular}




\begin{tabular}{|c|c|c|c|c|c|c|}
\hline $\begin{array}{l}\text { chalk } \\
\text { cave }\end{array}$ & $\begin{array}{c}\text { developing } \\
\text { promotional } \\
\text { activities }\end{array}$ & 32.300 .000 & & 748.000 & other academic activities & 25.900 .000 \\
\hline 87 & promotion strategy & 3.030 .000 & white eggs & 26.000 .000 & thesis supervisor & 20.400 .000 \\
\hline 88 & target audience & 19.800 .000 & long shape & 422.000 .000 & scholarship studies & 158.000 .000 \\
\hline 89 & second step & 28.300 .000 & seasonal bird & 32.900 .000 & study extension & 376.000 .000 \\
\hline 90 & positive impact & 842.000 .000 & certain season & 175.000 .000 & graduate designations & 533.000 \\
\hline 91 & visitor annularity & 514.000 & second kinds & 353.000 .000 & master program & 730.000 .000 \\
\hline 92 & next step & 215.000 .000 & dark black feather & 6.100 .000 & doctorate program & 24.300 .000 \\
\hline 93 & $\begin{array}{c}\text { promotional } \\
\text { messages }\end{array}$ & 32.400 .000 & brown feather & 20.400 .000 & interest study & 856.000 .000 \\
\hline 94 & general action & 1.610 .000 .000 & spacious tail & 619.000 & unstructured curriculum & 455.000 \\
\hline 95 & $\begin{array}{l}\text { prospective } \\
\text { consumers }\end{array}$ & 41.200 .000 & loud and rattled sound & 624.000 & structured curriculum & 42.000 .000 \\
\hline 96 & loyal customers & 46.300 .000 & biggest species & 78.400 .000 & master program life cycle & 10.800 .000 \\
\hline 97 & high involvement & 3.870 .000 & fly faster ad higher & 10.500 .000 & internship report paper & 1.560 .000 \\
\hline 98 & many times & 311.000 .000 & small cave & 81.400 .000 & graduating paper & 28.400 .000 \\
\hline 99 & promotional budget & 869.000 .000 & small gap & 272.000 .000 & job descriptions & 19.000 .000 \\
\hline 100 & appropriate media & 596.000 .000 & bowl-shaped nests & 1.350 .000 & $\begin{array}{c}\text { academic administration } \\
\text { staff }\end{array}$ & 364.000 .000 \\
\hline
\end{tabular}

Sumber: Data Pribadi 


\section{Lampiran 2}

\section{Daftar frekuensi hasil pencarian P4-P6}

\begin{tabular}{|c|c|c|c|c|c|c|}
\hline No. & P4 & $\begin{array}{c}\text { Jumlah Hasil } \\
\text { Pencarian } \\
\text { Google }\end{array}$ & $\mathrm{P}_{5}$ & $\begin{array}{c}\text { Jumlah Hasil } \\
\text { Pencarian } \\
\text { Google }\end{array}$ & P6 & $\begin{array}{c}\text { Jumlah Hasil } \\
\text { Pencarian } \\
\text { Google }\end{array}$ \\
\hline 1 & economic activity & 14.900 .000 & brief profile & 174.000 .000 & main staple foods & 6.170 .000 \\
\hline 2 & $\begin{array}{c}\text { production and } \\
\text { consumption activities }\end{array}$ & 144.000 .000 & $\begin{array}{c}\text { modern islamic boarding } \\
\text { school }\end{array}$ & 480.000 & Chinese influence & 155.000 .000 \\
\hline 3 & $\begin{array}{c}\text { usefulness of goods and } \\
\text { services }\end{array}$ & 614.000 .000 & story of establishment & 282.000 .000 & many varieties & 72.700 .000 \\
\hline 4 & everyday life & 104.000 .000 & islamic boarding school & 893.000 & chicken noodle & 4.590 .000 \\
\hline 5 & $\begin{array}{c}\text { good distribution } \\
\text { channels }\end{array}$ & 5.030 .000 & boarding school & 18.400 .000 & Chinese descent & 4.050 .000 \\
\hline 6 & availability of products & 617.000 .000 & greatly indebted & 3.150 .000 & historical records & 236.000 .000 \\
\hline 7 & $\begin{array}{c}\text { production and } \\
\text { distribution activities }\end{array}$ & 312.000 .000 & royal title & 322.000 .000 & mainland China & 11.200 .000 \\
\hline 8 & $\begin{array}{c}\text { various factors of } \\
\text { production }\end{array}$ & 45.400 .000 & fourth generation & 6.990 .000 & reign of Han dynasty & 793.000 \\
\hline 9 & $\begin{array}{c}\text { good distribution } \\
\text { activities }\end{array}$ & 5.850 .000 & three kilometers away & 25.900 .000 & European continent & 60.000 .000 \\
\hline 10 & distribution company & 26.400 .000 & forested area & 8.420 .000 & continental Europe & 7.120 .000 \\
\hline 11 & distribution process & 741.000 .000 & early days & 54.400 .000 & gift shop noodles & 837.000 \\
\hline 12 & group of persons & 412.000 .000 & number of students & 1.060 .000 .000 & well-known & 372.000 .000 \\
\hline 13 & other entities & 43.900 .000 & dedicated students & 392.000 .000 & street food & 72.100 .000 \\
\hline 14 & economic needs & 643.000 .000 & survival of Gontor & 36.000 & small restaurant & 470.000 .000 \\
\hline 15 & human beings & 58.300 .000 & surrounding villages & 47.900 .000 & $\begin{array}{c}\text { medium-class } \\
\text { restaurant }\end{array}$ & 958.000 \\
\hline 16 & existence of companies & 168.000 .000 & previously very religious & 281.000 .000 & high-class restaurant & 10.600 .000 \\
\hline 17 & key players & 220.000 .000 & bad thing & 515.000 .000 & much money & 993.000 .000 \\
\hline
\end{tabular}




\begin{tabular}{|c|c|c|c|c|c|c|}
\hline 18 & Indonesian economy & 19.400 .000 & thought hard & 535.000 .000 & highly recommended & 377.000 .000 \\
\hline 19 & community members & 1.320 .000 .000 & worked really hard & 328.000 .000 & $\begin{array}{c}\text { original and delicious } \\
\text { taste }\end{array}$ & 58.200 .000 \\
\hline 20 & new order & 94.500 .000 & fifth child & 5.000 .000 & other mie ayam stalls & 81.700 \\
\hline 21 & grassroots communities & 30.600 .000 & $\begin{array}{c}\text { other educational } \\
\text { institution }\end{array}$ & 226.000 .000 & best weapons & 21.300 .000 \\
\hline 22 & marketing activities & 348.000 .000 & Islamic calendar & 8.290 .000 & increased enormously & 13.300 .000 \\
\hline 23 & necessary goods & 351.000 .000 & assembled audience & 18.000 .000 & city center & 284.000 .000 \\
\hline 24 & $\begin{array}{c}\text { works effectively and } \\
\text { efficiently }\end{array}$ & 73.200 .000 & three brothers & 17.500 .000 & $\begin{array}{c}\text { index success of } \\
\text { business }\end{array}$ & 202.000 .000 \\
\hline 25 & ditribution of goods & 206.000 .000 & first step & 249.000 .000 & affordable price & 361.000 .000 \\
\hline 26 & $\begin{array}{c}\text { number of important } \\
\text { tasks }\end{array}$ & 241.000 .000 & $\begin{array}{c}\text { child educational } \\
\text { program }\end{array}$ & 368.000 .000 & strategic areas & 307.000 .000 \\
\hline 27 & critical information & 23.400 .000 & coconut shells & 2.140 .000 & several places & 545.000 .000 \\
\hline 28 & $\begin{array}{l}\text { planning and launching } \\
\text { exchange }\end{array}$ & 67.600 .000 & plaited mats & 188.000 & residental areas & 395.000 .000 \\
\hline 29 & persuasive information & 43.600 .000 & later developed & 668.000 .000 & boarding house areas & 1.510 .000 \\
\hline 30 & service offers & 1.290 .000 .000 & many branch & 460.000 .000 & seven branches & 87.200 .000 \\
\hline 31 & buyer demands & 19.700 .000 & many regions & 328.000 .000 & good thing & 1.010 .000 .000 \\
\hline 32 & final agreement & 18.100 .000 & first building & 1.610 .000 .000 & one branch & 483.000 .000 \\
\hline 33 & transfer of ownership & 225.000 .000 & each boarding school & 2.170 .000 & unique factors & 355.000 .000 \\
\hline 34 & physical distribution & 4.620 .000 & some lists & 481.000 .000 & $\begin{array}{c}\text { one of popular mie } \\
\text { ayam sellers }\end{array}$ & 7.690 .000 \\
\hline 35 & storage of goods & 210.000 .000 & education institution & 428.000 .000 & $\begin{array}{l}\text { uniqueness of the } \\
\text { products }\end{array}$ & 23.500 .000 \\
\hline 36 & funding requests & 10.100 .000 & leader cadres & 1.280 .000 & eyes of the customers & 76.700 .000 \\
\hline 37 & marketing channel & 9.850 .000 & source of Islamic sciences & 2.830 .000 & $\begin{array}{l}\text { improvements of the } \\
\text { products and services }\end{array}$ & 228.000 .000 \\
\hline 38 & duct work & 6.270 .000 & language of Al-Qur'an & 2.360 .000 & more specific data & 1.200 .000 .000 \\
\hline 39 & five first tasks & 180.000 .000 & sciences knowledge & 493.000 .000 & three main branches & 83.400 .000 \\
\hline 40 & $\begin{array}{c}\text { completion of the } \\
\text { transaction }\end{array}$ & 28.100 .000 & religious character & 109.000 .000 & several customers & 432.000 .000 \\
\hline
\end{tabular}




\begin{tabular}{|c|c|c|c|c|c|c|}
\hline 41 & company overview & 499.000 .000 & excellent graduates & 71.400 .000 & main factors & 441.000 .000 \\
\hline 42 & talented businessmen & 444.000 & new generation & 120.000 .000 & $\begin{array}{l}\text { improvement and } \\
\text { development of the } \\
\text { products }\end{array}$ & 221.000 .000 \\
\hline 43 & $\begin{array}{c}\text { specialized solutions } \\
\text { technology }\end{array}$ & 1.550 .000 & noble character & 1.370 .000 & some information & 5.570 .000 .000 \\
\hline 44 & $\begin{array}{c}\text { industries and business } \\
\text { functions }\end{array}$ & 7.900 .000 & sound body & 19.000 .000 & following methods & 51.100 .000 \\
\hline 45 & $\begin{array}{c}\text { distributor of consumer } \\
\text { electronics }\end{array}$ & 675.000 & broad knowledge & 13.400 .000 & direct observation & 9.390 .000 \\
\hline 46 & system integrator & 2.830 .000 & independent mind & 4.850 .000 & valid data & 622.000 .000 \\
\hline 47 & reliable experience & 350.000 .000 & science religion & 228.000 .000 & main data & 1.430 .000 .000 \\
\hline 48 & $\begin{array}{c}\text { comprehensive } \\
\text { capabilities }\end{array}$ & 2.250 .000 & another science & 811.000 .000 & some photographs & 275.000 .000 \\
\hline 49 & high performance & 313.000 .000 & teach proportionally & 1.580 .000 & additional data & 2.060 .000 .000 \\
\hline 50 & technical team & 524.000 .000 & intellectual Moslem & 16.300 .000 & operational manager & 13.400 .000 \\
\hline 51 & project cost & 671.000 .000 & Indonesian personality & 740.000 & $\begin{array}{l}\text { company history and } \\
\text { products }\end{array}$ & 504.000 .000 \\
\hline 52 & every organization & 807.000 .000 & five spirit & 311.000 .000 & related books & 589.000 .000 \\
\hline 53 & vendor neutral & 981.000 & boarding system & 51.200 .000 & related products & 372.000 .000 \\
\hline 54 & $\begin{array}{c}\text { selection of technology } \\
\text { solutions }\end{array}$ & 7.060 .000 & Islamic brotherhood & 988.000 & objectives of the study & 237.000 .000 \\
\hline 55 & $\begin{array}{c}\text { audio-visual and } \\
\text { multimedia system }\end{array}$ & 1.460 .000 & organization structure & 37.100 .000 & $\begin{array}{l}\text { methods of collecting } \\
\text { data }\end{array}$ & 105.000 .000 \\
\hline 56 & refrigeration system & 3.120 .000 & highest position & 608.000 .000 & brief information & 2.560 .000 .000 \\
\hline 57 & true integrated ordering & 64.600 .000 & boarding guidance & 11.800 .000 & company profile & 749.000 .000 \\
\hline 58 & $\begin{array}{c}\text { installation of electronic } \\
\text { equipment }\end{array}$ & 97.400 .000 & some institutions & 272.000 .000 & organizational structure & 24.000 .000 \\
\hline 59 & all-in-one solution & 247.000 .000 & widely known & 14.500 .000 & $\begin{array}{c}\text { three different } \\
\text { branches }\end{array}$ & 156.000 .000 \\
\hline 60 & $\begin{array}{l}\text { communications } \\
\text { company-wide }\end{array}$ & 17.600 .000 & only Islamic University & 3.370 .000 & $\begin{array}{l}\text { strength and weak } \\
\text { point }\end{array}$ & 7.800 .000 \\
\hline 61 & Audio-Visual lines up & 24.800 .000 & $\begin{array}{l}\text { Arabic and English } \\
\text { teaching medium }\end{array}$ & 1.570 .000 & whole research & 1.060 .000 .000 \\
\hline
\end{tabular}




\begin{tabular}{|c|c|c|c|c|c|c|}
\hline 62 & video-conference & 33.900 .000 & two languages & 355.000 .000 & early business & 880.000 .000 \\
\hline 63 & tele-conference & 4.160 .000 & $\begin{array}{c}\text { medium of } \\
\text { communication }\end{array}$ & 242.000 .000 & culinary business & 29.600 .000 \\
\hline 64 & control system & 174.000 .000 & $\begin{array}{c}\text { language academic } \\
\text { assignments }\end{array}$ & 41.700 .000 & first agreement & 25.000 .000 \\
\hline 65 & touch-screen panel & 28.000 .000 & research report & 1.650 .000 .000 & couple times & 407.000 .000 \\
\hline 66 & installation accessories & 108.000 .000 & whole facilities & 503.000 .000 & many years & 1.820 .000 .000 \\
\hline 67 & digital signage & 10.700 .000 & single system & 1.610 .000 .000 & $\begin{array}{c}\text { actually unprepared } \\
\text { specifically }\end{array}$ & 2.990 .000 \\
\hline 68 & service solutions & 72.900 .000 & $\begin{array}{c}\text { routine activities and } \\
\text { programs }\end{array}$ & 594.000 & useful things & 318.000 .000 \\
\hline 69 & broadcast station & 122.000 .000 & regular progress report & 9.690 .000 & some activity & 1.070 .000 .000 \\
\hline 70 & humidity control & 83.800 .000 & regularly forwarded & 33.200 .000 & little business & 67.800 .000 \\
\hline 71 & $\begin{array}{c}\text { fresh air supply } \\
\text { ventilation }\end{array}$ & 1.070 .000 & director of the school & 859.000 .000 & lack of experience & 386.000 .000 \\
\hline 72 & $\begin{array}{c}\text { advanced climate } \\
\text { control }\end{array}$ & 32.000 .000 & main duty & 422.000 .000 & culinary background & 8.240 .000 \\
\hline 73 & $\begin{array}{c}\text { optimally comfortable } \\
\text { indoor environment }\end{array}$ & 602.000 & $\begin{array}{c}\text { main duty of the } \\
\text { foundation }\end{array}$ & 102.000 .000 & existing business & 42.800 .000 \\
\hline 74 & real values & 603.000 .000 & $\begin{array}{c}\text { Waqf maintenance and } \\
\text { enlargement }\end{array}$ & 20.300 & run perfectly & 1.600 .000 .000 \\
\hline 75 & water chillers & 604.000 & waqf land & 271.000 & new business & 3.050 .000 .000 \\
\hline 76 & $\begin{array}{c}\text { variable refrigerant } \\
\text { volume }\end{array}$ & 137.000 & $\begin{array}{l}\text { program of the } \\
\text { foundation }\end{array}$ & 942.000 .000 & new system & 3.150 .000 .000 \\
\hline 77 & other manufacturers & 389.000 .000 & productivity of the land & 97.300 .000 & second choice & 45.400 .000 \\
\hline 78 & variable refrigerant flow & 339.000 & family welfare & 10.600 .000 & $\begin{array}{l}\text { some things } \\
\text { interestingly }\end{array}$ & 50.200 .000 \\
\hline 79 & extremely efficient & 18.000 .000 & self finance & 14.100 .000 & major priority & 259.000 .000 \\
\hline 80 & energy saving ways & 4.730 .000 & family association & 26.200 .000 & close connection & 566.000 .000 \\
\hline 81 & types of buildings & 301.000 .000 & meeting place & 41.100 .000 & academic background & 227.000 .000 \\
\hline 82 & $\begin{array}{c}\text { minimum installation } \\
\text { time }\end{array}$ & 226.000 .000 & different regions & 327.000 .000 & $\begin{array}{c}\text { mechanical engineering } \\
\text { program }\end{array}$ & 32.800 .000 \\
\hline 83 & best system & 1.800 .000 .000 & student organization & 37.900 .000 & human beings & 57.800 .000 \\
\hline
\end{tabular}




\begin{tabular}{|c|c|c|c|c|c|c|}
\hline 84 & currently available & 1.320 .000 .000 & media of learning & 1.090 .000 .000 & middle and upper class & 6.070 .000 \\
\hline 85 & $\begin{array}{l}\text { mid to large } \\
\text { applications }\end{array}$ & 161.000 .000 & $\begin{array}{l}\text { whole activities of } \\
\text { students }\end{array}$ & 175.000 .000 & restaurant concept & 96.400 .000 \\
\hline 86 & mechanical device & 17.500 .000 & main aim & 465.000 .000 & middle-lower class & 2.170 .000 \\
\hline 87 & heat exchange & 11.200 .000 & $\begin{array}{l}\text { well qualified Muslim } \\
\text { leader }\end{array}$ & 602.000 & first business & 2.370 .000 .000 \\
\hline 88 & closed loop system & 8.800 .000 & student union & 15.100 .000 & restaurant business & 550.000 .000 \\
\hline 89 & special partners & 573.000 .000 & other university & 2.650 .000 .000 & noodle stall & 462.000 \\
\hline 90 & installation devices & 233.000 .000 & student activities & 25.300 .000 & alternative staple food & 2.470 .000 \\
\hline 91 & $\begin{array}{c}\text { main distribution } \\
\text { strategies } \\
\end{array}$ & 7.410 .000 & one of devotion place & 26.200 .000 & favorite food & 382.000 .000 \\
\hline 92 & distribution strategy & 9.920 .000 & $\begin{array}{c}\text { management and } \\
\text { community development }\end{array}$ & 50.900 .000 & hard effort & 429.000 .000 \\
\hline 93 & major concern & 310.000 .000 & business management & 2.280 .000 .000 & simple tools & 433.000 .000 \\
\hline 94 & any company & 2.640 .000 .000 & rural development & 57.200 .000 & beginning of creation & 39.800 .000 \\
\hline 95 & role of distribution & 625.000 .000 & social service & 143.000 .000 & home-made noodle & 15.500 .000 \\
\hline 96 & right time & 3.280 .000 .000 & surrounding communities & 132.000 .000 & main target & 468.000 .000 \\
\hline 97 & minimum cost & 654.000 .000 & $\begin{array}{c}\text { students language } \\
\text { activities }\end{array}$ & 416.000 .000 & better person & 56.400 .000 \\
\hline 98 & source of production & 1.050 .000 .000 & daily activities & 567.000 .000 & true identity & 14.300 .000 \\
\hline 99 & analytical plan & 124.000 .000 & department of teaching & 533.000 .000 & biggest company & 357.000 .000 \\
\hline 100 & strategy of distribution & 310.000 .000 & learning process & 1.310 .000 .000 & wet noodle & 464.000 \\
\hline
\end{tabular}

Sumber: Data Pribadi 